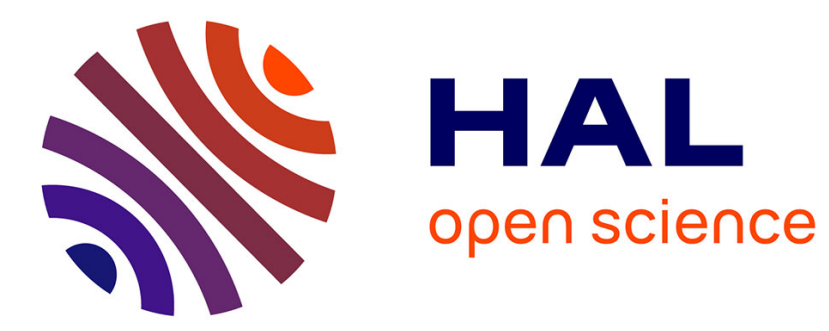

\title{
Deux exemples d'usages politiques des Gaulois à la fin du XVe siècle
}

Franck Collard

\section{To cite this version:}

Franck Collard. Deux exemples d'usages politiques des Gaulois à la fin du XVe siècle: Dédicace par Robert Gaguin à Charles VIII de sa traduction des Commentaires de César (1485) et Extrait du discours du chancelier Guillaume de Rochefort devant les députés des États généraux de Tours (1484). Parlement[s], Revue d'histoire politique, 2020, "Nos ancêtres les Gaulois! ", 2020/2 (32), pp.133. 10.3917/parl2.032.0133 . hal-03116637

\section{HAL Id: hal-03116637 https://hal.parisnanterre.fr/hal-03116637}

Submitted on 20 Jan 2021

HAL is a multi-disciplinary open access archive for the deposit and dissemination of scientific research documents, whether they are published or not. The documents may come from teaching and research institutions in France or abroad, or from public or private research centers.
L'archive ouverte pluridisciplinaire $\mathbf{H A L}$, est destinée au dépôt et à la diffusion de documents scientifiques de niveau recherche, publiés ou non, émanant des établissements d'enseignement et de recherche français ou étrangers, des laboratoires publics ou privés. 


\title{
DEUX EXEMPLES D'USAGES POLITIQUES DES GAULOIS À LA FIN DU XV SIĖCLE.
}

\author{
DÉDICACE PAR ROBERT GAGUIN À CHARLES VIII \\ DE SA TRADUCTION DES COMMENTAIRES DE CÉSAR \\ (1485) ET EXTRAIT DU DISCOURS DU CHANCELIER \\ GUILLAUME DE ROCHEFORT DEVANT LES DÉPUTÉS \\ DES ÉTATS GÉNÉRAUX DE TOURS (1484)
}

\author{
Franck Collard \\ Professeur d'histoire médiévale, \\ Université Paris Nanterre, Chisco EA 1587 \\ fcollard arobase parisnanterre.fr
}

«A tres christien et tres excellent prince Charles huitiesme de ce nom, roy de France, Robert, ministre general de l'Ordre de saincte Trinité et redemption des prisonniers christiens, dit et desire en toute humilité, honneur, gloire et longue vie.

Orace la poete dit que scavoir faire chose plaisante et aggreable aux princes terriens n' est point petite vertu ne à mettre entre les dernieres et tres singulieres louenges et bieneuretez de l'omme. Et croy que la cause de son dit si est pour ce que les princes voient et oyent chascun jour tant de haultes et merveileuses choses que celui est de fort bon engin et inventif qui leur scait et peut faire dire ou escrire chose gracieuse et a leur goust. Pour cette raison, j'ay beaucoup craint de prendre entree et congnoissance en si haulte et excellente court comme est la vostre, doubtant que ma petitesse ne peust actaindre ne advenir a faire chose en laquelle votre Haultesse et Majesté print plaisir et delectacion, jusques a ce que puis na gueres, il vous a pleu et recevoir debonnairement et prendre en gré le petit livre des faiz du glorieux empereur et roy sainct Charlemaine mis 
par moy et translaté de latin en françoys; et oultre ce, qu'il vous pleut a me commander que je achevasse et acomplisse diligemment la translacion des commentaires Julles Cesar par moy pieca commencée. Laquelle vostre debonnaireté et ordonnance m'a donné hardiesse de poursuivir soubz esperance que mon euvre et labour vous seront aulcunement a plaisance et prouffitables, non qui soit en moy mais pour la grandeur des choses contenues es livres originaux desquelz j'ai entreprins la translacion. Car comme deux choses soient premierement requises et fort convenables, a ung souverain prince, c'est a scavoir prudence de conduire en bon ordre les choses publiques et force de mener vaillamment et de couraige les guerres quant il en est besoing, vous trouverez l'une et l'autre choses en ce livre, lequel Julles Cesar escript de ses mesmes faiz et entreprinses lesquelles il fist en $\mathrm{X}$ ans qu'il eust la charge du peuple de Romme de gouverner la province de Gaule, pendant lequel temps il eut congnoissance a l'œil de toutes les contrees et de tous les fors lieux de la terre de Gaule en laquelle vostre royaulme est situé et assiz, et lequel comprend la plus grande partie d'icelle terre; et par ce il vous apperra quelles condicions, quelles meurs et quelle conduite, quelle puissance, quelle force et quelle maniere de vivre chascune gent estant soubz vostre gouvernement et seignorie avoient deslors, et comment encores ilz retreuvent aulcunes choses de ce temps la. Et ce vous peut beaucoup prouffiter a conduire et gouverner chacune nacion selon l'inclinacion naturelle et coustume ancienne, laquelle ne se peut changier par rigueur ou violence sans bruit ou dommaige. Et quant a ce qui touche les fais de chevallerie et de guerre, vous congnoistrez en ce livre le conseil et meure deliberacion qu'on doibt avoir avant qu'on commence discord ne guerre et comment on ne doibt estre legier ne soudain a croire mauvaiz raportz ne a entreprendre grans et perilleux affaires telz comme sont guerres par lesquelles l'estat des princes et de toutes communautés et choses publicques est souvent enversé, perdu et deffait. Et pour ce que en lisant vous apperceverez quelle utilité ce livre vous pourra faire, je dirai seulement la raison pour quoy il est appellé commentaire. Si fault entendre que ce mot commentaire, en tant qui sert a nostre propos, vault autant a dire comme briesve exposicion. Et pour ce que Jules Cesar n'a escript des euvres qu'il fist en la terre de Gaule fors les principales et plus dignes 
de memoire, et encore il ne les a pas escriptes fort au long, pensant que le sommaire d'icelles souffiroit pour memoire a ceulx qui les vouldroient apres escrire et exposer plus au large. A ceste cause ce que Cesar a escript de ses faiz est appellé le livre des commentaires sur le fait des batailles de Gaule comme une briesve et sommaire narration de ses euvres, desquelles il parle comme se aultre que luy les escripvoit. En ce faisant, il nous donne congnoissance de moult de choses servant a la gloire du pays de Gaule et de vostre royaulme; en telle façon que lisant le grant nombre et assemblees des gens de guerre et les dures rencontres, les sieges et merveilleuses batailles des Gauloys faites contre Cesar, il ne semble pas qu'il escripve les fais d'une nacion seulement mais de tout le monde. De toutes lesquelles anciennes merveilles nous n'avons congnoissance que autant que Cesar en a escript en ce livre. Et ce se n'estoit ceste presente euvre, je ne vois point comment on peust parler au vray que c'estoit de ceste region de Gaule par avant que les premiers Fraçoys venissent par deça gaigner et fonder le commencement de si ample et puissant royaulme comme est le vostre. Mais a tant je me tairay afin que vous oyez parler le principal acteur Jules Cesar duquel, en lisant, vous congnoistrez la vertu et incomparable diligence plus que nul autre empereur ou chef de guerre."

Dédicace par Robert Gaguin à Charles VIII de sa traduction des Commentaires de Jules César, 1485; édition originale, Paris, 1485, chez Pierre Levet, puis 1488; ms fr 728 et fr. 1392 de la BnF Éd. Louis Thuasne, Epistole et orationes Gaguini, Paris, 1903, réimpr. Genève, Slatkine, 1977, t. 2, p. 299-308, d'après le texte de l'editio princeps.

« [...] Quant aux vertus brillantes de ses habitants [les Galli du texte latin], j'ose affirmer que par leurs unions de cour, par l'honnêteté, par la politesse, par leur urbanité, ils excellent au-dessus du reste des nations. S'il est question de guerres, les armes gauloises, levées sur Rome, tête du monde, ne l'ont-elles pas prise et vaincue? N'ont-elles pas, après la mort d'Alexandre le Grand, voyagé impunément par tout l'Orient et par tout le Midi, dont elles ont soumis les populations? Et, quoique de nombreuses histoires nous parlent clairement de l'invincible énergie du courage gaulois, Salluste surtout 
nous la représente, en racontant que les Romains et leurs maîtres ne cessèrent de lutter contre la Gaule à la vie et à la mort; mais qu'ils ne se battirent avec les autres peuples que pour la gloire, et qu'ayant trouvé chez eux une victoire facile et des triomphes tout prêts, ils ne rencontrèrent, en face des Gaulois, que des combats difficiles et un bonheur douteux. Jules César, le premier monarque des Romains et le dompteur de l'empire, aidé principalement d'une armée gauloise, put vaincre Pompée et le sénat. De ces faits, il me sera permis de conclure que les Gaulois ont soumis le monde, eux qui ont triomphé de ses triomphateurs, et les ont tellement abattus que, par la suite, ils n'ont jamais eu la puissance de se remettre en leur primitive liberté. Disons du moins avec Juvénal : "Ils vengent l'univers vaincu".

Je n'oublierai pas de rappeler que leurs armes ont encore défendu fréquemment le siège apostolique et restitué le patrimoine de saint Pierre. Mais quelle nation chrétienne fit plus souvent la guerre aux infidèles? Laquelle a remporté sur eux plus de triomphes, et se tint plus pure des monstres de l'hérésie? Aucune sûrement, puisque, à cause de cette piété, le roi et son royaume ont obtenu le nom et le surnom de "très-chrétien" [...]. »

Extrait du discours du chancelier Guillaume de Rochefort devant les députés des États généraux de Tours, 15 janvier 1484. Éd. tr. Adhelm Bernier, Journal des États généraux de France tenus à Tours en 1484 sous le règne de Charles VIII rédigé en latin par Jehan Masselin, Paris, 1835, p. 39-41.

\section{cos}

L'humaniste Gaguin a fait précéder sa traduction de César, promise à un beau succès éditorial, d'un prologue adressé au roi de France Charles VIII, dont il s'était promis d'amplifier la faible culture résultant de l'éducation très déficiente que lui avait fait donner son père. Ce prologue très intéressant est fort différent du prologue que Pierre Bersuire avait dédié à Jean le Bon à l'occasion de sa traduction des Décades de Tite-Live. Bersuire ignorait la question gauloise au profit d'une réflexion sur la puissance romaine ${ }^{1}$.

1 Arsenal, ms. 3693. 
Gaguin agrège quant à lui clairement les anciens Gaulois au passé français et confond en grande partie le territoire du royaume avec celui des Gaules. Sortant de la traduction d'une Vie de Charlemagne (sans doute la Vita Karoli de Donato Acciaiuoli), il se consacre à un passé plus reculé mais non moins significatif et utile pour le roi. La connaissance des Gaulois n'est pas seulement nécessaire à cause de l'utilité de connaitre le passé en général pour imiter l'action des bons et méditer le sort des méchants - c'était le but de la traduction de Duchesne, prévenir le duc son maître des dangers de la tyrannie incarnée par César - ni pour enseigner au fils de Louis XI l'art de la guerre, mais bien parce que les mœurs des anciens habitants des Gaules ainsi que leurs coutumes n'ont pas changé et qu'il ne faut pas les brusquer en les gouvernant dans l'ignorance de ces mœurs, sous-entendu contrairement à ce qu'a fait le père du jeune monarque. Certes le docteur en décret artésien, qui sait bien toute la diversité du regnum Francorum, n'unifie pas les sujets de Charles VIII en une seule gens qui descendrait des Gaulois; il perçoit le royaume comme un agrégat de " gents " au pluriel (ce qu'était la Gaule du reste). Mais il ne leur affecte pas moins des mœurs communes et des vertus vantées par César et transmises par les siècles. Mettant les Commentaires au-dessus des autres sources, voire les instituant comme seule source valable sur le passé gaulois ("ad fontes»), l'auteur du Compendium marque, bien plus dans ce prologue que dans son abrégé d'histoire de France, son dessein d'agrégation du passé gaulois à l'identité heureuse - de la France.

Le discours du chancelier de Rochefort du 15 janvier 1484 est de la même veine. Manifestement inspiré par la lettre de Burgos dans laquelle Gaguin, provoqué par des interlocuteurs ibériques vantant leur pays aux dépens de la France, avait répliqué en mettant la gloire des Gaulois au compte de la grandeur française, le chancelier reprend la même vision continuiste. Gaguin exaltait la bravoure gauloise en évoquant Brennus, les migrations, racontées par Justin, des Galli en Grèce, leur résistance acharnée contre César qui n’aurait jamais vaincu ses adversaires s'ils avaient été unis. Puis, sans solution de continuité, il passe aux vertus guerrières des rois francs. Rochefort estime comme Gaguin que la défaite gauloise face aux légions romaines doit moins à la puissance de celles-ci qu'à la discorde des 
vaincus. C'est le premier épisode d'une incapacité chronique à s'unir face à l'ennemi. Les mêmes causes produisant les mêmes effets, les Français déchirés par la guerre civile ont subi la défaite face aux Anglais. Le chancelier exhorte donc les députés à éviter de nouvelles dissensions fatales au royaume. Puis il les galvanise en célébrant les victoires franques remportées dans le sillage des succès gaulois. 